\title{
Fungal Contaminants of Smoke-Dried Fish Sold in Open Markets in Makurdi, Benue State, North-Central Nigeria
}

\author{
Chinedu Adive Akwuobu1 ${ }^{*}$, Williams Senen Antiev¹, Raphael Agbo-Peters Ofukwu² \\ ${ }^{1}$ Department of Veterinary Microbiology, Federal University of Agriculture, Makurdi, Nigeria \\ ${ }^{2}$ Department of Veterinary Public Health and Preventive Medicine, Federal University of Agriculture, Makurdi, Nigeria \\ Email: *chineduakwuobu@yahoo.com
}

How to cite this paper: Akwuobu, C.A., Antiev, W.S. and Ofukwu, R.A.-P. (2019) Fungal Contaminants of Smoke-Dried Fish Sold in Open Markets in Makurdi, Benue State, North-Central Nigeria. Food and Nutrition Sciences, 10, 290-297.

https://doi.org/10.4236/fns.2019.103022

Received: January 30, 2019

Accepted: March 16, 2019

Published: March 19, 2019

Copyright () 2019 by author(s) and Scientific Research Publishing Inc. This work is licensed under the Creative Commons Attribution International License (CC BY 4.0).

http://creativecommons.org/licenses/by/4.0/

\begin{abstract}
This mycological study was embarked upon to provide more detailed reports on the presence and different types of fungal agents associated with the contamination of smoke-dried fish sold in open markets in Makurdi, Benue State. A total of 100 randomly selected smoke-dried fish samples from the 3 major fish markets in the study area were used for the study. The samples were aseptically processed and cultured for fungal isolation using Sabouraud Dextrose Agar. Isolates were identified using macroscopic and microscopic characteristics, and comparison with species in fungal atlas. Fungi were detected in 74 of the 100 smoke-dried fish samples from the 3 markets surveyed with isolation rates ranging from $67.6 \%$ to $84.8 \%$. A total of 77 fungal isolates were recorded from the 74 positive samples. Aspergillus (28.6\%), Mucor (20.8\%), Penicillum (18.2\%) and Rhizopus (15.6\%) were the dominant fungi detected, while Absidia (9.1\%) and Candida (7.8\%) occurred less frequently. In view of the high fungal contamination of smoke-dried fish, fishermen and marketers should adapt better methods of fish handling and preservation. More awareness on the health implications of fungal contamination of fish products should be created among fish handlers and consumers.
\end{abstract}

\section{Keywords}

Contamination, Fungi, Aspergillus, Smoke-Drying, Fish, Species

\section{Introduction}

The smoking processes of fish are of two forms viz. wet hot smoking and dry hot smoking [1]. Both processes are carried out at temperatures high enough to cook the fish. Wet hot smoking usually takes about $1-2$ hours and yields a moist, 
versatile product with about 40 - 55 percent moisture content, while dry hot smoking, which is usually preceded by the former process, takes about $10-18$ hours, sometimes days and yields fish with 10 - 15 percent moisture content. In the tropical countries such as Nigeria, Akande and Tobor [2] and Olokor et al. [3] documented that smoke-drying of fish is one of the oldest available local forms of preservation methods essentially employed by most fishing communities. Smoke-drying, apart from giving the product desirable taste and odour, preserves and prolongs the shelf-life of fish products conveniently at ambient conditions through its anti-bacterial and oxidative effects, lowering of $\mathrm{pH}$, imparting desirable colouration, accelerating the drying process and acting as antagonist to spoilage agents [2] [4] [5] [6] [7].

Consumption of smoked and smoke-dried fish without further cooking is common in Nigeria. It has been reported that smoke-dried fish are often contaminated with microorganisms such as bacteria, yeasts and moulds from the processing units to market centres [7] [8]. It was noticed that good storage practices are not observed by most wholesalers of smoked and smoke-dried fishes such as improper ventilation and easy access of pest into the storage environment [7] [9]. Banwart [10] also observed that most of the post processing microbial contaminants originate from poor handling practices, while some could be from the air, the source of the fish, or from other degrading substances [11]. In humid tropical conditions, Banwart [10] reported that very dry smoked fish with low moisture contents are prone to insect infestation, while others having medium to high moisture contents are predisposed to both bacterial and fungal contaminations [11].

Several fungal agents associated with the contamination of smoked and smoke-dried fishes, such as Aspergillus, Penicillum, Zygomycetes and yeasts are known to be opportunistic pathogens [12] causing varying degrees of health problems to both animals and man. Swaminathan and Sparling [13] reported that numerous pathogenic agents isolated from different types of fish were toxigenic, and their toxins retained in fish flesh even after salting and storage periods which causes serious systemic dysfunctions and public health hazards [7]. Corroborating the report of Swaminathan and Sparling [13], Tournas et al. [14] pointed out that most mycotoxins are stable compounds that are not destroyed during food processing or home cooking, and several cases of human gastroenteritis, severe diarrhoea and food poisoning outbreaks have been recorded after smoked fish consumption [7].

Despite the numerous reports on the fungal contaminants of smoke-dried fish in Nigeria and its public health implications, documented reports and studies on the mycology of smoke-dried fish in Makurdi and Benue State in general are pauce. Thus the need for this mycological study embarked upon to provide more information on the presence and different types of fungal species associated with the contamination of smoke-dried fish sold in open markets in Makurdi, Benue State, North-Central Nigeria. 


\section{Materials and Methods}

\subsection{Study Area}

The study was conducted in Makurdi, the capital city of Benue State in north-central Nigeria. The geographic coordinates of the capital city are longitude $8^{\circ} 32^{\prime} 00^{\prime \prime}$ and latitude $7^{\circ} 44^{\prime} 00^{\prime \prime}$ [15]. Makurdi is inhabited mainly by civil servants, paramilitary, soldiers, traders, fishermen, farmers, and craftsmen. It is known for its warm, humid and tropical climate which favours the growth of many microorganisms. The town is also rich in natural resources, and the River Benue supports maritime trade and fishing

\subsection{Sample Collection}

Smoke-dried fish samples used in this study were randomly selected and purchased, from October 2015 to March 2016, from Wurukum, Wadata and North-Bank markets which were the three major fish markets in the study area. A total of 100 fish samples was used for the study, and were collected in well-labeled sterile polythene bags and transported to the laboratory for processing and analysis for presence of fungi.

\subsection{Isolation and Identification of Fungal Agents}

The fish samples were aseptically processed for fungal isolation following the procedure described by Oyebamiji and Oyebimpe [16]. Each of the fish samples was blended and $5 \mathrm{~g}$ suspended in $10 \mathrm{ml}$ of sterile distilled water. A drop of the suspension of each blended fish sample was inoculated on Sabouraud Dextrose Agar (Life-Safe Biotech) plates. The plates were sealed with masking tape to prevent contamination by crawling insects and were then incubated at room temperature by placing the inoculated plates on a clean bench in the laboratory. The plates were then examined daily for fungal growth for $2-3$ weeks.

Isolates were identified using macroscopic (cultural characteristics), microscopic morphologies and comparison with already identified species in relevant fungal atlas [12] [17].

\subsection{Data Analysis}

The frequencies and market distributions of fungal isolates were determined using proportion and rates. The results were presented in tables and figure.

\section{Results and Discussion}

Samples from 74 of the 100 smoke-dried fish examined, showed fungal contamination (Table 1). The rates of fungal contamination of smoke-dried fish sold in Wurukum, Wadata and North Bank markets in Makurdi were very high ranging from $67.6 \%$ to $84.8 \%$. This finding reveals that smoke-dried fish sold in major markets in Makurdi, Benue State, North-central Nigeria are contaminated by fungi. Similar findings were reported in similar mycological studies on smoke-dried fish sold in markets in different parts of Nigeria [6] [7] [11] [16] [18]-[23]. 
Table 1. Distribution of fungal contaminants of smoke-dried fish in three markets in Makurdi Metropolis.

\begin{tabular}{ccc}
\hline Market & No. sampled & No. $(\%)^{*}$ positive \\
\hline Wurukum & 30 & $21(70.0)$ \\
Wadata & 33 & $28(84.8)$ \\
North-Bank & 37 & $25(67.6)$ \\
Total & 100 & $\mathbf{7 4}(74.0)$ \\
\hline
\end{tabular}

* $=\%$ of total number sampled for each row.

In Jos, Junaid et al. [19] reported fungal contamination rate of $100 \%$ of smoke-dried fish samples while Job et al. [6] recorded contamination rates ranging from 15\% - 85\%. Ayuba et al. [21] and Ayuba et al. [11], in their studies on microbial load of smoked fish sold in the different markets in Makurdi, did not report the rates of fungal contamination of the fish sampled. Similar results were reported in Uyo [18], Ibadan [16] [22] and Maiduguri [7].

The reported high fungal contamination of smoke-dried fish could be associated, as observed by Eyo [5], Akande and Tobor [9] and Sani et al. [7], with the handling of fish which could engender microbial contamination especially in artisanal fishery due to unhygienic methods of reducing temperature. During the smoke-drying period, Eyo [5] and Akande and Tobor [9] cited by Sani et al. [7] pointed out that smoking kilns used in artisanal fishery and the overloading of the fish in the trays leads to improper processing which in turn encourages fungal attack. In addition, post-processing handling and storage, according to Okiya and Akeodi [24], may be responsible for the presence of high numbers of fungi in the smoked fish samples at the points of sale; and it could also be a result of survival of the spores of these organisms during the heat treatment and their subsequent germination afterward [20]. Thus the growth of fungi in smoke-dried fish can be affected by the storage method employed. It was observed, during sample collection for the present study, that smoke-dried fishes were stored either in baskets, wooden boxes or metal containers with covers. Osibona et al. [23] observed in their study that storage containers play a vital role in the preservation and shelf-life of smoked dried fish, and recommended the use of airtight storage containers for smoked fish.

A total of 77 fungal isolates were recorded from the 74 positive smoke-dried fish samples examined (Table 2). Twenty-three (29.9\%) fungal isolates were recorded for Wurukum market while 28 (36.4\%) and 26 (33.8\%) were recorded for Wadata and North Bank markets respectively. The number of fungal isolates in this study was more than the number of smoke-dried fish samples positive for fungi due to mixed growth of fungi in some samples. Junaid et al. [19] similarly reported obtaining 139 fungal isolates from 100 smoked fish samples due to mixed growth in combinations of 2 or 3 fungi. Job et al. [6] obtained 164 fungal isolates from 60 samples. Sani et al. [7] also reported mixed growth in various combinations of fungi. 
Table 2. Frequencies of fungal isolates in smoke-dried fish in three markets in Makurdi Metropolis.

\begin{tabular}{ccccc}
\hline \multirow{2}{*}{ Fungal isolate } & \multicolumn{3}{c}{ Market (\%)* } & \multirow{2}{*}{ Total (\%)** } \\
\cline { 2 - 4 } & Wurukum & Wadata & North-Bank & \\
\hline Aspergillus niger & $4(17.4)$ & $3(10.7)$ & $4(15.4)$ & $11(14.3)$ \\
Aspergillus flavus & $2(8.7)$ & $4(14.3)$ & $3(11.5)$ & $9(11.7)$ \\
Aspergillus fumigatus & $1(4.3)$ & $0(0.0)$ & $1(3.8)$ & $2(2.6)$ \\
Penicillum species & $6(26.1)$ & $4(14.3)$ & $4(15.4)$ & $14(18.2)$ \\
Mucor species & $4(17.4)$ & $6(21.4)$ & $6(23.7)$ & $16(20.8)$ \\
Rhizopus species & $3(13.0)$ & $5(17.9)$ & $4(15.4)$ & $12(15.6)$ \\
Absidia species & $0(0.0)$ & $4(14.3)$ & $3(11.5)$ & $7(9.1)$ \\
Candida species & $3(13.0)$ & $2(7.1)$ & $1(3.8)$ & $6(7.8)$ \\
Total $(\%)^{* *}$ & $23(29.9)$ & $28(36.4)$ & $26(33.8)$ & $77(100)$ \\
\hline
\end{tabular}

${ }^{*}=\%$ of total number of isolates for each market; ${ }^{* *}=\%$ of overall number of isolates (77).

The present study revealed that fungal genera associated with contamination of smoke-dried fish sold in Makurdi were Aspergillus, Penicillum, Mucor, Rhizopus, Absidia and Candida species (Table 2). Aspergillus (28.6\%), Mucor (20.8\%), Penicillum (18.2\%) and Rhizopus (15.6\%) were the dominant fungi recorded in association with the smoke-dried fish contamination. Absidia (9.1\%) and Candida (7.8\%) occurred less frequently. Members of Zygomycetes (Mucor, Rhizopus and Absidia species), taken as a group (Figure 1), recorded the highest isolation rate (45.5\%). Aspergillus isolates obtained in this study were identified, as shown in Table 2, as A. niger 11 (14.3\%), A. flavus 9 (11.7\%) and A. fumigatus 2 (2.6\%). Aspergillus niger and A. flavus were the dominant species. The only yeast identified in this study was Candida species

Many fungal organisms associated with the contamination of smoke-dried fish sold in markets in Nigeria have been reported in different studies [6] [7] [11] [16] [18] [19] [20] [21] [22]. In Makurdi, Ayuba et al. [11] and Ayuba et al. [21] respectively isolated and identified 4 and 2 fungal genera associated with smoked fish. The isolates reported by Ayuba et al. [11] were Aspergillus niger, Alternaria species, Mucor species and unidentified yeast while Ayuba et al. [21] identified only Aspergillus niger and Mucor species. The present study in Makurdi revealed that other fungal organisms such as Aspergillus flavus, Aspergillus fumigatus, Penicillum, Rhizopus, Absidia and Candida species were also fungal contaminants of smoke-dried fish. However, Alternaria species were not identified in this study. Sani et al. [7] reported Aspergillus fumigatus, Aspergillus niger, Candida albicans, Mucor species, Penicillium species, Trichophyton rubrum, Microsporum audunii, Candida tropicalis, Candida stellatoidea as fungi associated with smoke-dried fish sold in Maiduguri metropolis. Contrary to our findings, Sani et al. [7] isolated Trichophyton rubrum and Microsporum audunii from smoke-dried fish and did not isolate Aspergillus flavus, Rhizopus and Absidia 


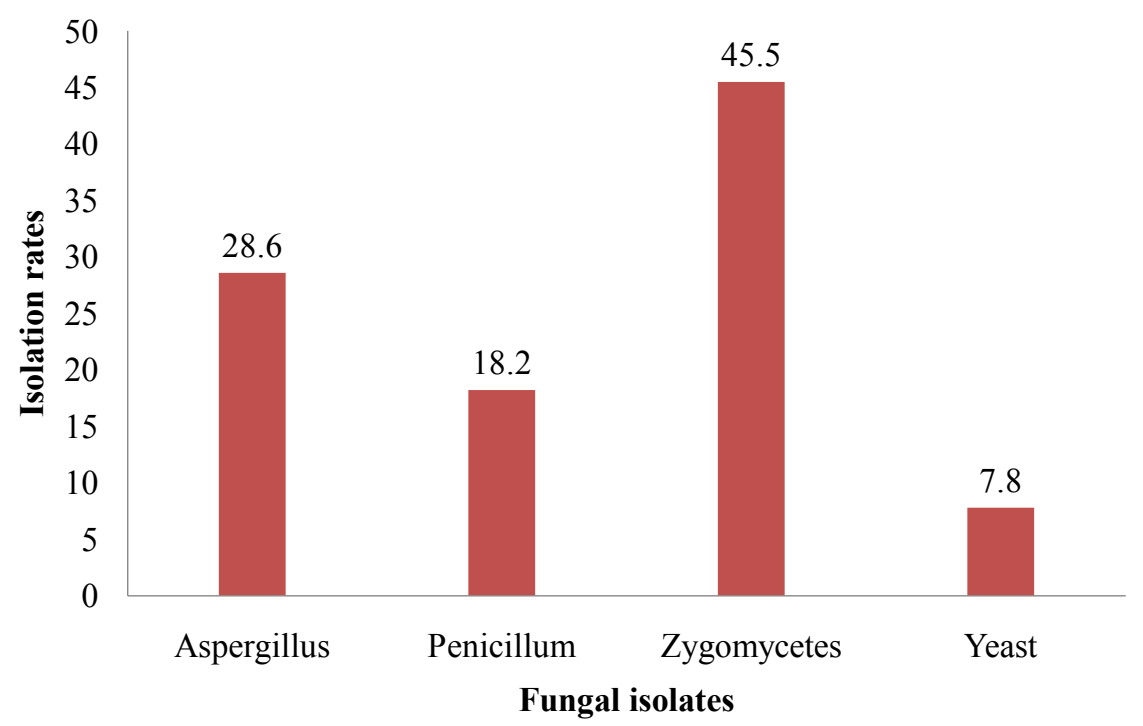

Figure 1. Percentage occurrence of fungal isolates in smoke-dried fish in Makurdi Metropolis.

species. In Jos, Junaid et al. [19] reported the isolation of Trichophyton verrucosum in addition to Aspergillus, Mucor, Rhizopus, Penicillum and no yeasts. While in another study in Jos, Job et al. [6] identified many yeasts and no dermatophytes as contaminants of smoke-dried fish. Fusarium species, in addition to Aspergillus, Penicillum and Rhizopus species were identified by Jimoh et al. [22] in Ibandan.

The contamination of smoke-dried fish by many different species of fungi, as observed in this study and many other earlier studies, is not surprising because, according to Akande and Tobor [9] cited by Sani et al. [7], the environment where fish are displayed in the market are usually unhygienic and could constitute another avenue for microbial contamination. Akande and Tobor [9] and Sani et al. [7] correctly observed that very often, retailers display the smoke-dried fish samples in open trays beside refuse heaps which encourages fungal attack through air droplets.

The fungi isolated in this study are all opportunistic pathogens [12] of medical and veterinary importance. The presence of toxigenic fungi, for example some species of Aspergillus, Penicillium and Candida, in foods as contaminants increases the risk for mycotoxins production which could induce gastrointestinal and metabolic disturbances when contaminated foods like smoke-dried fish are consumed [25] [26]. Among the moulds isolated by Job et al. [6], only strains of Aspergillus flavus presented aflatoxigenic producing potentials. However, Osibona et al. [23] detected aflatoxin and ochratoxin A in stored fish samples as a result of the presence of Aspegillus and Penicillium species; while Bukola et al. [18] detected aflatoxins $B_{1}$ and $G_{1}$ in all the species of Aspergillus isolated in their study in Uyo. Nevertheless, Sani et al. [7] opined that many fungal genera have virulence factor which cause toxin elaboration under favourable predisposing environment. 


\section{Conclusion}

The present study revealed that smoke-dried fish sold in open markets in Makurdi metropolis are contaminated with different species of moulds some of which are known toxigenic fungi of human and animal health significance. In view of the high fungal contamination of smoke-dried fish in the study area, as a result of poor handling, processing and storage, fishermen and marketers should adapt better methods of preservation (drying and storage). Also more awareness on the health implications of fungal agents and mycotoxins associated with contaminated fish products should be created among fish handlers and consumers.

\section{Acknowledgements}

We are grateful to the Department of Veterinary Pathology and Microbiology, College of Veterinary Medicine, Federal University of Agriculture, Makurdi for making her laboratory available for this study.

\section{Conflicts of Interest}

None of the authors have any conflict of interest.

\section{References}

[1] Agriculture Nigeria Online Hub. https://agriculturenigeria.com/agro-processing/processing-of-animals/fish-processi ng/fish-smoking

[2] Akande, G. and Tobor, J. (1993) Forms in Which Fish Is Preserved before Consumption in Nigeria. Fish Net., 1-15.

[3] Olokor, J., Ihuahi, J., Omojowo, F., Falayi, B. and Adelowo, E. (2007) Handbook of Practical Fisheries Technology. Fisheries Technology Division, National Institute for Freshwater Fisheries Research (NIFFR), New Bussa.

[4] Sengor, G., Kalafatoglu, H. and Gun, H. (2004) The Determination of Microbial Flora, Water Activity and Chemical Analysis in Smoked Mussels (Mytilus galloprovincialis, L.). Turkish Journal of Veterinary and Animal Sciences, 28, 793-797.

[5] Eyo, A. (2012) Traditional and Improved Fish Handling, Preservation and Processing Techniques. NAERLS/NIFER National Workshop on Fish Process Storage, Marketing and Utilization, 15-20.

[6] Job, M.O., Agina, S.E. and Dapiya, H.S. (2016). Occurrence of Aflatoxigenic Fungi in Smoke-dried Fish Sold in Jos Metropolis. British Microbiology Research Journal, 11, 1-7. https://doi.org/10.9734/BMRJ/2016/21465

[7] Sani, F.M., Nasir, I.A. and Torhile, G. (2016) Mycological Evaluation of Smoked-Dried Fish Sold at Maiduguri Metropolis, Nigeria: Preliminary Findings and Potential Health Implications. European Journal of Health Sciences, 2, 5-10. https://doi.org/10.5505/eurjhs.2016.69885

[8] Okafor, N. and Nzeako, B. (1985) Microbial Flora of Fresh and Smoked Fish from Nigerian Fresh Water. Food Microbiology, 2, 71-5. https://doi.org/10.1016/0740-0020(85)90025-5

[9] Akande, G. and Tobor, J. (2012) Improved Utilization and Increased Availability of Fishing Products as an Effective Control of Aggravated Animal Protein Deficiency Induced Malnutrition in Nigeria. Proceedings of the 10 th Annual Conference of the 
Fisheries Society of Nigeria, 18-31.

[10] Banwart, G.J. (2004) Basic Food Microbiology. 2nd Edition, CBS Publishers \& Distributors, New Delhi.

[11] Ayuba, V.O., Alhassan, M. and Jimmy, U. (2013) Assessment of the Microbial Load of Smoked Sardine (Sardina pilchardus, Walbaum, 1792) Sold in Makurdi Markets. International Journal of Current Microbiology and Applied Sciences, 2, 277-287.

[12] Hungerford, L., Campbell, C. and Smith, A. (1998) Common Opportunistic or Contaminant Fungi. In: Veterinary Mycology Laboratory Manual, Iowa State University Press, Iowa, 58-60.

[13] Swaminathan, B. and Sparling, P. (1998) The Bacteriology of Food Excluding Dairy Products. In: Collier, L., Balows, A. and Sussman, M., Eds., Microbiology and Microbial Infection, 9th Edition, Edward Arnold Publishers Ltd., London, Vol. 2, 407-408.

[14] Tournas, V., Stack, M., Mislivec, P., Koch, H. and Bandler, R. (2001) Yeasts, Molds and Mycotoxins Mycological Analysis Manual. Food and Drug Administration, USA.

[15] Tageo.com: A Database of Geographic Coordinate Information. http://www.tageo.com/index-e-ni-v-26-d-m2807202.htm

[16] Oyebamiji, F. and Oyebimpe, F. (2013) Microbial Identification of Smoke-Dried Fish (Clarias gariepinus) from Some Local Markets in Ibadan Metropolis. Wudpecker Journal of Agricultural Research, 2, 294-298.

[17] Madigan, T.M., Martinko, J.M. and Stahl, D. (2009) Brock Biology of Microorganisms. Person International Incorporation Publishers, San Francisco.

[18] Bukola, C.A.-T., Abiodun, A.O. and Ukpe, G.P. (2008) Mycofloral of Smoke-Dried Fishes Sold in Uyo, Eastern Nigeria. World Journal of Agricultural Sciences, 4, 346-350.

[19] Junaid, S.A., Olarubofin, F. and Olabode, A.O. (2010) Mycotic Contamination of Stockfish Sold in Jos, Nigeria. Journal of Yeast and Fungal Research, 1, 136-141.

[20] Edema, M. and Agbon, A. (2010) Significance of Fungi Associated with Smoke-Cured Ethmalosa fimbriata and Clarias gariepinus. Journal of Food Processing and Preservation, 34, 355-363. https://doi.org/10.1111/j.1745-4549.2009.00426.x

[21] Ayuba, V., Onah, E. and Ataguba, G. (2012) Microbial Load on the African Catfish (Clarias gariepinus) Sold in Makurdi Metropolis: A Case Study of Selected Markets. 26th Annual Conference of the Fisheries Society of Nigeria, Minna, 16-24.

[22] Jimoh, W., Ayeloja, A., Oladele-Bukola, M., Adebayo, M., Azeez, A. and Salami, S. (2014) Isolation of Fungi Infesting Smoked African Catfish from Markets in Ibadan, Nigeria. Nigerian Journal of Fisheries and Aquaculture, 2, 13-17.

[23] Osibona, A.O., Ogunyebi, O.O. and Samuel, T.O. (2018) Storage Fungi and Mycotoxins Associated with Stored Smoked Catfish (Clarias gariepinus). Journal of Applied Sciences and Environmental Management, 22, 643-646.

[24] Okiya, A. and Akeodi, J. (1998) Comparative Study of Fungal Infestation of Three Traditionally Smoke-Dried Freshwater Fishes in Rivers State. Journal of Aquatic Science, 13, 41-43.

[25] Martin, A. (2008) Fish Processing: Biochemical Applications. Chapman and Hall, London.

[26] Bennett, J. and Klich, M. (2003) Mycotoxins. Clinical Microbiology Reviews, 16, 497-516. https://doi.org/10.1128/CMR.16.3.497-516.2003 